\title{
Investigating global correlations between tsunami, earthquake, and subduction zone characteristics
}

\author{
Iris van Zelst ${ }^{\mathrm{a}, *}$, Silvia Brizzi ${ }^{\mathrm{b}, \mathrm{c}}$, Elenora van Rijsingen ${ }^{\mathrm{d}, \mathrm{c}, \mathrm{e}}$, Francesca \\ Funicielloc $^{c}$, Ylona van Dinther ${ }^{a, f}$ \\ ${ }^{a}$ Seismology and Wave Physics, Institute of Geophysics, Department of Earth Sciences, \\ ETH Zürich, Zürich, Switzerland \\ ${ }^{b}$ Natural and Experimental Tectonics research group, University of Parma, Parma, Italy \\ ${ }^{c}$ Laboratory of Experimental Tectonics, Dip. Scienze, Roma Tre University, Rome, Italy \\ ${ }^{d}$ Laboratoire de Géologie, École Normale Supérieure, PSL Research University, \\ CNRS-UMR 8538, Paris, France \\ ${ }^{e}$ Géosciences Montpellier, CNRS, Montpellier University, Montpellier, France \\ ${ }^{f}$ Department of Earth Sciences, Utrecht University, Utrecht, The Netherlands
}

\begin{abstract}
Tsunamigenic earthquakes pose a large hazard in subduction zones, but it is currently unclear in which - if any - tectonic setting they preferentially occur. We compile the Subduction Nature \& Interconnected Tsunamigenic earthquake Characteristics (SNITCH) database with parameters on the geodynamics, megathrust seismicity, and tsunami characteristics for tsunamis caused by earthquakes in all subduction zones. We use a bivariate regression analysis to detect possible relationships between the tsunamigenic earthquake characteristics of a subduction zone and its interplate seismicity, as well as its geometric, structural, and kinematic parameters. We focus our analysis on the normalised number of tsunamigenic earthquakes $N_{t}$. The bivariate analysis does not reveal any significant correlations between $N_{t}$ and the seis-
\end{abstract}

\footnotetext{
*Corresponding author

Email address: iris.vanzelst@erdw.ethz.ch (Iris van Zelst)
} 
mogenic zone geometry of the megathrust. However, we do find correlations between $N_{t}$ and the megathrust seismicity and tectonic parameters characterising a subduction zone. We employ a multivariate Fisher analysis on the tectonic parameters to see which combinations best distinguish the subduction zone segments in which relatively many and few tsunamis occurred. We find that the type of margin (i.e., erosional or accretionary), the trenchnormal component of the subduction and convergence velocity, the amount of sediments at the trench and the roughness of the incoming plate are the most important parameters to achieve this. Therefore, tsunamigenic earthquakes may be more prone to occur in tectonic settings where plates subduct relatively fast beneath a sediment-starved, erosional margin. A complex, shallow subduction interface, characterised by multiple faults and fractures that arise at a margin with little trench sediments to smooth subducting plate topography, could account for the larger number of tsunamigenic earthquakes. These results could have implications for hazard assessment.

Keywords: tsunamis, earthquakes, tsunamigenic earthquakes, subduction zones, multivariate statistics, tectonics

\section{Introduction}

Tsunamigenic earthquakes are defined as earthquakes that cause tsunamis

7 quake and tsunami (e.g., Lay et al., 2005; Titov et al., 2005; Fujii et al., 
2011; Ozawa et al., 2011). During these large events, the megathrust typically plays the most important role, as it provides the largest potential slip area, and is therefore capable of producing the largest earthquake with an accompanying tsunami. However, other faults than the megathrust, such as outer rise or splay faults, likely play an important role in tsunamigenesis as „well (Fukao, 1979; Sibuet et al., 2007; Waldhauser et al., 2012; von Huene et al., 2016; Fan et al., 2017; Sladen and Trevisan, 2018). Since these faults have steeper dips than the megathrust, they can accommodate more vertical displacements for similar amounts of slip (Wendt et al. 2009). However, it is difficult to determine whether an earthquake ruptured along the megathrust or a splay fault, due to the uncertainty in earthquake and tsunami source localisation (Sibuet et al., 2007; Waldhauser et al., 2012).

․ Tsunami earthquakes are a subset of tsunamigenic earthquakes (Satake and Tanioka, 1999; Satake, 2015). They are defined by their disproportionally large tsunami waves compared to their seismic waves (Kanamori, 1972). Other characteristics of tsunami earthquakes include their slow rupture velocity and long rupture duration (Kanamori, 1972). It is typically thought that they rupture the shallowest part of the subduction interface (Lay et al. 2012), where the rocks contain many fluids and are velocity-strengthening and compliant (Bilek and Lay, 1999; Faulkner et al., 2011; Sahakian et al., 2019). Since tsunami earthquakes could pose an even larger, unexpected hazard than regular tsunamigenic earthquakes, studies have typically focused on the possible mechanisms behind tsunami earthquakes and which type of subduction setting might be more prone to produce them (Polet and Kanamori, 2000; Bilek and Lay, 2002; Geersen, 2019). Based on these studies, two 
subduction zone parameters in particular are associated with tsunami earthquakes: the amount of sediments at the trench and the roughness of the subducting plate.

Tsunami earthquakes are typically associated with sediment-starved, erosional margins, because these settings can sustain very shallow slip due to their shallow frictional regime (Polet and Kanamori, 2000; Bilek, 2010; Geersen, 2019). However, it has also been suggested that sediment-rich margins could promote several aspects typical for tsunami earthquakes. The lower rigidity and strength of sediments could for example facilitate the slow tsunami earthquake rupture (Polet and Kanamori, 2000). Similarly, the sudden uplift of sediments in the unconsolidated accretionary wedge, which is typically larger in accretionary margins with large amounts of trench sediments, during an earthquake could account for large vertical displacements of the water column (Seno, 2002; Tanioka and Seno, 2001).

The degree of roughness of an incoming plate is defined by the size and distribution of topographic features, such as seamounts, horst and graben structures, and ridges. Generally, tsunami earthquakes are associated with rough incoming plates (Tanioka et al., 1997; Polet and Kanamori, 2000; Geersen, 2019). For example, observations of past tsunami earthquakes, such as the 1947 Offshore Poverty Bay and Tolaga Bay earthquakes, have shown that ruptures could be affected by seamounts (Bell et al., 2014). Most notably, it has been speculated that the low rupture velocities typically associated with tsunami earthquakes stem from rupture on a seamount (Bell et al., 2014). Other structural features on the incoming plate, such as subducting fracture zones (Robinson et al., 2006) or ridges (Gahalaut et al. 2010), have also been 
proposed to influence the rupture and its velocity.

The observed relationship between tsunami earthquakes, the amount of trench sediments in a subduction zone, and incoming plate roughness appears to be contrary to the relationship observed for large $\left(\mathrm{M}_{\mathrm{w}}>8.5\right)$ megathrust earthquakes. Large megathrust earthquakes are typically associated with a smooth incoming plate and a large trench sediment thickness (Ruff, 1989; Heuret et al., 2012; Wang and Bilek, 2014; Scholl et al., 2015; Brizzi et al., 2018; Van Rijsingen et al., 2018). However, it is unclear how tsunamigenic earthquakes, which include both tsunami earthquakes and some large megathrust earthquakes, are affected by trench sediments and incoming plate roughness. A global assessment, including statistics on the relationship between tsunamigenic earthquakes and general subduction zone characteristics, is still missing.

Here, we combine a subduction zone characteristics and megathrust seismicity database with a tsunami database. For the first time, we provide a global overview of parameters playing a role in the tsunamigenic earthquake process. We investigate the relationships between tsunamigenic earthquakes, megathrust seismicity, and the tectonic setting of subduction zones. Using bi- and multivariate statistical analyses, we identify subduction zone characteristics associated with the occurrence of tsunamigenic earthquakes. We find that fast-converging systems where an oceanic plate subducts at a sediment-starved, erosional margin are more prone to produce tsunamigenic earthquakes. 


\section{The SNITCH database}

We compile a database containing information on megathrust seismicity, seismogenic zone geometry, subduction zone tectonics, and tsunami events. We call this database the Subduction Nature \& Interconnected Tsunamigenic earthquake Characteristics (SNITCH) database. The SNITCH database consists of two parts: SNITCH-SN is a subduction zone database containing data on subduction zones characteristics and megathrust seismicity presented in Heuret et al. (2011, 2012); Brizzi et al. (2018); Lallemand et al. (2018). SNITCH-T consists of characteristics of tsunamis caused by earthquakes compiled from NOAA NGDC/WDS Global Historical Tsunami data Global Historical Tsunami Database, Retrieved: February 1, 2019). In the following, we describe how we assembled the SNITCH database in detail.

\subsection{SNITCH-SN: Subduction nature}

We use the subduction zone characteristics database of Brizzi et al. (2018), which is based on the database of Heuret et al. (2011, 2012). This database consists of 62 subduction zone segments (Fig. 1) derived from merging 505 subduction zone transects based on homogeneous megathrust seismicity, homogeneous seismogenic zone geometry, or rupture areas for $M_{w} \geq 8.0$ earthquakes confined in a single segment.

We do not consider the trench-parallel extent of the subduction zone and upper plate nature parameters from the database presented in Brizzi et al. (2018), as they only provide limited physical meaning. We also do not consider the relative upper plate, trench, and subducting plate velocities in this database. Instead, we focus on the subduction and convergence velocities 
independent of any reference frame to describe the kinematics of the system (DeMets et al., 1990).

We add the parameters $L^{*}$ and $W_{\text {interplate }}$ from Heuret et al. (2011) as measures for the along-strike length of the subduction segment and the seismogenic zone width, respectively. We also include two new parameters that quantify the roughness of the seafloor of the incoming plate prior to subduction according to Lallemand et al. (2018): long (i.e., 80-100 km) and short (i.e., 12-20 km) wavelength roughness. These parameters serve as a proxy for the roughness on the subduction interface. The different wavelengths are sensitive to different styles of topographic features on the subducting plate. Short wavelength roughness is typically associated with small- and intermediate-sized seamounts. Long wavelength roughness typically relates to large seamounts, seamount chains, and oceanic ridges. To translate the data provided by Lallemand et al. (2018) to the format of the 62 subduction zone segments used here, we average the roughness values for all transects comprising one subduction segment. Our final SNITCH-SN database has 25 different parameters (Table 1).

The AvsE parameter denotes the type of margin in a subduction segment and can be either accretionary or erosional. Accretionary wedges are defined as margins where mass is being accreted over long periods of geological time (>10 Myr). In contrast, mass is eroded at erosional margins. Material accretion can be facilitated through material transfer from the subducting plate to the overriding plate, by scraping off material at the trench or underplating (Clift and Vannucchi, 2004). Accretionary margins can also experience short-lived periods of erosion. Similarly, erosional margins can experience 
periods of accretion. For example, the Nankai subduction segment is an accretionary margin which experienced short periods of erosion (Clift and Vannucchi, 2004). These erosional periods could be induced by the subduction of, for instance, a seamount. According to Clift and Vannucchi (2004), accretionary margins are typically associated with slow convergence rates $v_{\mathrm{cn}}$ and larger trench sediment thickness $T_{\text {sed }}$. In contrast, erosional margins favour rapidly converging systems with less sediment cover $(<1 \mathrm{~km}) \overline{\text { Clift }}$ and Vannucchi, 2004).

We sort the SNITCH-SN parameters in three different categories to simplify the analysis: megathrust seismicity, geometric, and tectonic parameters. The megathrust seismicity parameters result from earthquake observations from the ISC-GEM Global Instrumental Earthquake (Storchak et al., 2013) and Centennial-Harvard CMT catalogues spanning from 1900 up to 2007 (see Heuret et al., 2011; Brizzi et al., 2018, for more details). The geometric parameters of the seismogenic zone are derived from megathrust seismicity from 1900 to 2007 according to Heuret et al. (2011) (Fig. 3). Therefore, the geometric parameters only shed light on the geometry of the seismogenic zone along the megathrust and do not include information on the geometry of the downgoing slab, overriding plate, splay or outer rise faults. $W_{\text {intraslab }}$ considers the entire downdip length of the slab and is derived from all intraslab earthquakes recorded in the area. The tectonic parameters are independent of any earthquake catalogue, and give insight into the nature of the subducting and overriding plate, the large scale geometry of the system, such as the distance between the volcanic arc and the trench $D_{\text {arc-trench }}$, and the kinematics of the subduction zone. 
Table 1: Parameters in the SNITCH-SN database: subduction nature

\begin{tabular}{|c|c|c|}
\hline Symbol & Parameter & Unit \\
\hline \multicolumn{3}{|c|}{ Megathrust seismicity parameters } \\
\hline$N_{e q}$ & Number of earthquakes & - \\
\hline$\tau$ & $\begin{array}{l}\text { Seismicity rate: number of events per century and } \\
\text { per } 10^{3} \mathrm{~km} \text { trench }\end{array}$ & - \\
\hline$C S M$ & Cumulative seismic moment & $\mathrm{N} \mathrm{m}$ \\
\hline$M_{\mathrm{mrr}}$ & $\begin{array}{l}\text { Equivalent representative magnitude in the sense } \\
\text { of Ruff and Kanamori }(1980)\end{array}$ & - \\
\hline$M_{\max , \mathrm{GEM} 1900}$ & $\begin{array}{l}\text { Maximum } M_{w} \text { from } 1900-2007 \text { according to the } \\
\text { ISC-GEM catalogue }\end{array}$ & - \\
\hline$M_{\max , \mathrm{Cent} \& \mathrm{CMT}}$ & $\begin{array}{l}\text { Maximum } M_{w} \text { from } 1900-2007 \text { according to the } \\
\text { Centennial \& CMT catalogues }\end{array}$ & - \\
\hline$M_{\max , \mathrm{GEM} 1960}$ & $\begin{array}{l}\text { Maximum } M_{w} \text { from } 1960-2007 \text { according to the } \\
\text { ISC-GEM catalogue }\end{array}$ & - \\
\hline \multicolumn{3}{|c|}{ Geometric parameters (based on seismicity) } \\
\hline$z_{\min }$ & Depth of the updip limit of the seismogenic zone & $\mathrm{km}$ \\
\hline$z_{\max }$ & Depth of the downdip limit of the seismogenic zone & $\mathrm{km}$ \\
\hline$x_{\min }$ & $\begin{array}{l}\text { Distance from the trench of the updip limit of the } \\
\text { seismogenic zone }\end{array}$ & $\mathrm{km}$ \\
\hline$x_{\max }$ & $\begin{array}{l}\text { Distance from the trench of the downdip limit of } \\
\text { the seismogenic zone }\end{array}$ & $\mathrm{km}$ \\
\hline$W_{\text {interplate }}$ & Downdip width of the seismogenic zone & $\mathrm{km}$ \\
\hline
\end{tabular}




\begin{tabular}{|c|c|c|}
\hline$\theta$ & Dip of the megathrust & $\circ$ \\
\hline$R$ & Curvature radius of the slab at the trench & $\mathrm{km}$ \\
\hline$W_{\text {intraslab }}$ & Downdip length of the slab & $\mathrm{km}$ \\
\hline \multicolumn{3}{|c|}{ Tectonic parameters } \\
\hline$L^{*}$ & $\begin{array}{l}\text { Trench-parallel extent of the subduction zone seg- } \\
\text { ment }\end{array}$ & $\mathrm{km}$ \\
\hline$A$ & Age & Myr \\
\hline$D_{\text {arc-trench }}$ & $\begin{array}{l}\text { Mean distance between the volcanic arc and the } \\
\text { trench }\end{array}$ & $\mathrm{km}$ \\
\hline UPS & $\begin{array}{l}\text { Upper plate strain } \\
1=\text { extension }(E) ; 2=\text { neutral }(N) ; 3=\text { compres- } \\
\text { sion }(C)\end{array}$ & - \\
\hline$T_{\text {sed }}$ & Sediment thickness at the trench & $\mathrm{km}$ \\
\hline AvsE & $\begin{array}{l}\text { Type of margin } \\
0=\operatorname{accretionary}(A) ; 1=\operatorname{erosional}(E)\end{array}$ & - \\
\hline$R_{\mathrm{sw}}$ & Short wavelength roughness $(12-20 \mathrm{~km})$ & $\mathrm{m}$ \\
\hline$R_{\mathrm{lw}}$ & Long wavelength roughness (80-100 km) & $\mathrm{m}$ \\
\hline$v_{\mathrm{sn}}$ & $\begin{array}{l}\text { Trench-normal component of the subduction ve- } \\
\text { locity from DeMets et al. (1990) }\end{array}$ & mm year ${ }^{-1}$ \\
\hline$v_{\mathrm{cn}}$ & $\begin{array}{l}\text { Trench-normal component of the convergence ve- } \\
\text { locity from DeMets et al. }(1990)\end{array}$ & mm year ${ }^{-1}$ \\
\hline
\end{tabular}




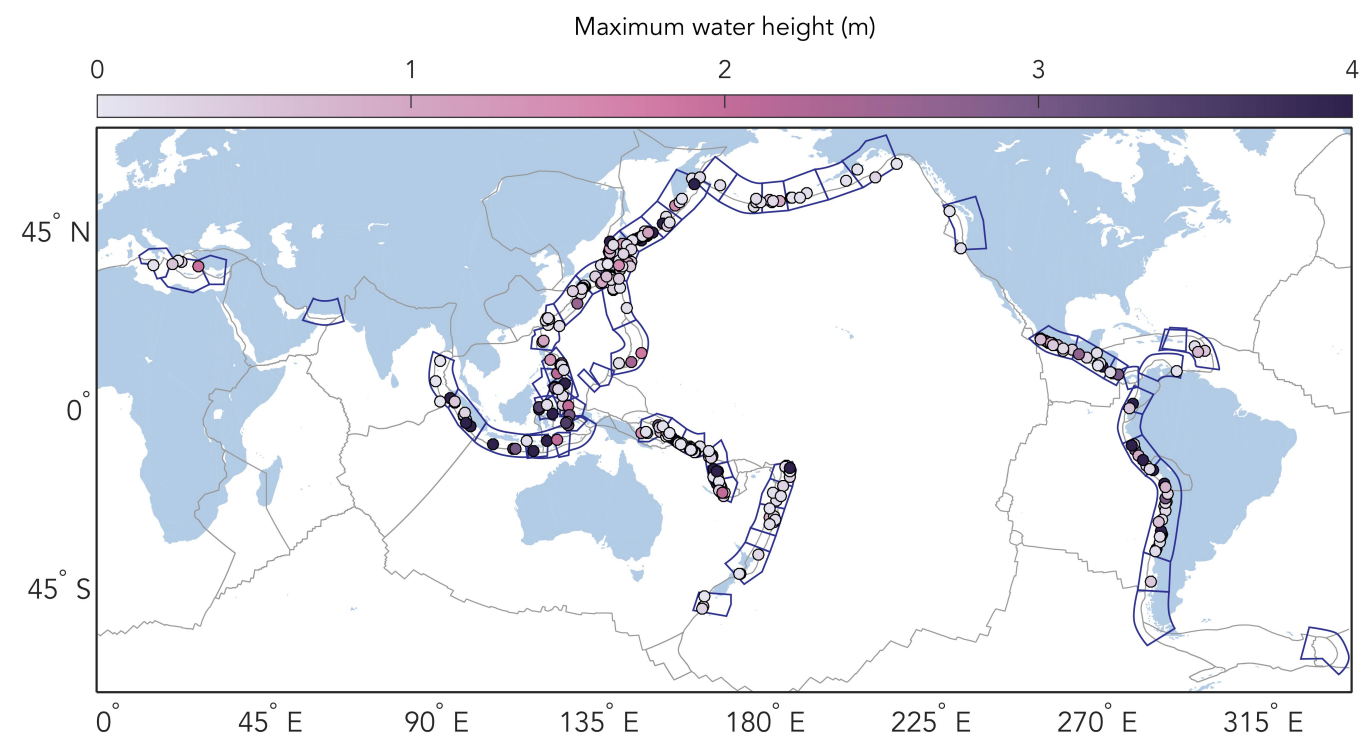

Figure 1: All 329 definite tsunami events caused by an earthquake in the NOAA NGDC/WDS Global Historical Tsunami Database that occurred from 1962 to 2018, organised into the subduction zone segments (dark blue) defined by Heuret et al. (2011). Events are coloured by maximum observed water height.

\subsection{SNITCH-T: Tsunamigenic earthquakes}

We download data from the NOAA NGDC/WDS Global Historical Tsunami

Database (Global Historical Tsunami Database, Retrieved: February 1, 2019).

We choose this database over the Global Tsunami Database of the Novosibirsk Tsunami Laboratory of the Institute of Computational Mathematics and Mathematical Geophysics of Siberian Division of Russian Academy of Sciences (NTL/ICMMG SD RAS; Global Tsunami Database, 2100 BC to Present, 2019), because the NOAA database is better suited for studying the statistics on the occurrence of tsunamis (Gusiakov et al., 2019). We select definite tsunami events that were caused by an earthquake from 1962-2018. We choose 1962 to start our data retrieval, because of the instalment of the 
World-Wide Standardised Seismograph Network that year, which ensured global monitoring of earthquakes. Prior to 1962, the NOAA NGDC/WDS Global Historical Tsunami Database is potentially incomplete. Using this time window, we extract 395 tsunamis. Because some of the parameters in the SNITCH-SN database are based on megathrust seismicity data up to 2007 (Sec. 2.1), we make a second version of the SNITCH-T database that is limited to 2007, which consists of 284 tsunamis. Hence, there are two versions of the SNITCH-T database: SNITCH-T-2007 and SNITCH-T-2018.

For each tsunami in the NOAA NGDC/WDS Global Historical Tsunami Database, we extract the tsunami source location (i.e., earthquake epicenter), maximum water height measured $h_{w}$, tsunami magnitude $M_{t}$, tsunami intensity $I_{t}$, earthquake magnitude $M_{w}$, and earthquake hypocenter depth $z_{f}$ (i.e., the focal depth).

The tsunami magnitude $M_{t}$ is defined as (Iida et al., 1967)

$$
M_{t}=\log _{2} h,
$$

where $h$ is the maximum runup height of the tsunami wave.

The tsunami intensity $I_{t}$ is defined as (Soloviev and Go, 1974)

$$
I_{t}=\log _{2}(\sqrt{2} \cdot h) .
$$

We sort all tsunamis into the subduction zone segments defined by Heuret et al. (2011) based on their tsunami source location. For the SNITCH-T2018 database, 66 events are situated outside the subduction zone segments. We remove these events from our analysis, as they are not associated with tsunamigenic earthquakes in subduction zones. This results in a total of 329 tsunamis in the SNITCH-T-2018 database (Fig. 1). In the SNITCH-T-2007 
database, 47 tsunamis are situated outside the subduction zone segments, so the final SNITCH-T-2007 database consists of 237 tsunamis.

As the subduction zone segments consist of rectangular transects, they can overlap in some places. If a tsunami is placed in an area where two or more subduction zone segments overlap, we manually place it in a segment. For this purpose, we consider the depth of the earthquake, which better suggests with which subducting plate, and hence which subduction zone segment, a tsunami should be associated. In total, there are 46 tsunamis $(14 \%$ of all tsunamis in SNITCH-T-2018) that are manually sorted into subduction zone segments following this procedure.

When all tsunami events are sorted in a subduction zone segment, we count the amount of tsunamis in each subduction zone $\left(N_{t, \text { tot }}\right)$ and calculate the normalised number of tsunamis per km trench $N_{t}$

$$
N_{t}=\frac{N_{t, \text { tot }} / L^{*}}{\max \left(\mathrm{N}_{\mathrm{t}, \mathrm{tot}} / \mathrm{L}^{*}\right)},
$$

where $L^{*}$ is the along-strike length of a subduction segment. For each segment, we also calculate the maximum water height among all events that occurred in that segment, the average maximum water height observed for the events, the maximum and average tsunami magnitude and intensity, the average and minimum focal depth, and the minimum, average, and maximum earthquake magnitude that caused a tsunami in that segment. We then have 13 parameters in the SNITCH-T database (Table 2). As the data in the NOAA NGDC/WDS Global Historical Tsunami Database is scarce for each tsunami, some subduction segments do not have values for all parameters. The only parameters for which we have a complete record for all subduction zone segments are $N_{t}$ and $N_{t, \text { tot }}$. We deem $N_{t}$ the most reliable quantity for 
Table 2: Parameters in the SNITCH-T database: tsunamigenic earthquakes

\begin{tabular}{llc}
\hline Symbol & Parameter & Unit \\
\hline$N_{t}$ & Normalised number of tsunamis per km trench & - \\
$N_{t, \text { tot }}$ & Total number of tsunamis in a subduction zone segment & $\mathrm{m}$ \\
$h_{w, \text { max }}$ & Maximum water height observed for an event in a segment & $\mathrm{m}$ \\
$\overline{h_{w}}$ & Average maximum water height of all events in a segment & - \\
$M_{t, \text { max }}$ & Maximum tsunami magnitude observed for an event in a segment & - \\
$\overline{M_{t}}$ & Average tsunami magnitude of all events in a segment & - \\
$I_{t, \text { max }}$ & Maximum tsunami intensity observed for an event in a segment & - \\
$\overline{I_{t}}$ & Average tsunami intensity of all events in a segment \\
$\overline{z_{f}}$ & Average earthquake focal depth of all events in a segment & $\mathrm{km}$ \\
$z_{f, \min }$ & Minimum earthquake focal depth in a segment & $\mathrm{km}$ \\
$M_{w, \text { max }}$ & Maximum earthquake magnitude in a segment & - \\
$\overline{M_{w}}$ & Average earthquake magnitude of all events in a segment & - \\
$M_{w, \text { min }}$ & Minimum earthquake magnitude in a segment & - \\
\hline
\end{tabular}

robust insights on the relationship between tectonics and tsunamigenesis as it is normalised and not dependent on the size of the subduction segments. Therefore, we focus our analysis on $N_{t}$.

\section{Bivariate statistical analysis}

\subsection{Methods}

We calculate the Pearson's product-moment correlation coefficient $R_{p}$ for SNITCH-T with itself and SNITCH-SN. The Pearson's product-moment correlation coefficient gives insight into the linear correlation between two vari- 
ables. To reduce the effect of outliers on linear correlations, we also calculate the Spearman rank correlation coefficient $\rho$, in which the similarity or monotonicity between two variables is assessed, regardless of any linear relationship that might exist between them.

To focus our analysis, we consider a relationship between two variables worthy of further investigation if both the Pearson and Spearman correlations are higher than or equal to 0.3 (Heuret et al., 2011) with $p$-values smaller than 0.05 (i.e., there is less than a $5 \%$ chance that the null hypothesis of there being no correlation is true). $p$-values for the Spearman correlations are indicated by $p$ and $p$-values for Pearson correlations are indicated by $p_{p}$. For visualising our results, we show the Spearman's rank correlation coefficient (Sec. 3.2), because it typically shows the highest correlations. This is due to the fact that the data is not linear, and can more easily be described by a monotonic relationship. However, the differences in correlation coefficients between the two methods is on average only a few percent. The results for Pearson's product-moment correlation coefficient can be found in the Supplementary Material.

\subsection{Results}

\subsubsection{Tsunamigenic earthquakes}

Fig. 2 shows the correlation matrix for the Spearman's rank correlation coefficients of SNITCH-T-2018 with itself. In this and the following figures, correlations that are significant under our definition in Sec. 3.1 are indicated by a red plus or minus sign depending on a positive or negative correlation, respectively. Additional scatter plots and numbers for the correlations and corresponding $p$-values can be found in the Supplementary Material. 
The normalised number of tsunamis per $\mathrm{km}$ trench $N_{t}$ and total number of tsunamis in a subduction zone segment $N_{t, \text { tot }}$ correlate positively with the maximum water height $h_{w, \max }(\rho=0.44$ and $\rho=0.56$, respectively), which relates to the fact that the likelihood of a tsunami with high maximum water height is larger when sufficient tsunami events occur in a given subduction zone. A similar reasoning can be applied to the correlations between $N_{t}$ and $N_{t, \text { tot }}$ and $M_{w, \max }(\rho=0.44$ and $\rho=0.49$, respectively), as a large number of tsunamigenic earthquakes in a subduction zone increases the likelihood of a big earthquake being the cause of such an event.

The maximum water height parameters and $M_{t, \max }$ also correlate positively with the maximum and average earthquake magnitude, which indicates that larger earthquakes produce larger wave heights and hence tsunami magnitudes and intensities.

The average focal depth of the tsunamigenic earthquakes correlates positively with the magnitude of the earthquake $(\rho=0.35)$, indicating that a larger earthquake magnitude corresponds to a deeper focal depth. This is reinforced by the correlation between the shallowest focal depth and the minimum earthquake magnitude $(\rho=0.43)$. Hence, large tsunamigenic earthquakes likely nucleate at larger focal depths.

\subsubsection{Megathrust seismicity}

The Spearman's rank correlation coefficient matrix of the tsunamigenic earthquake parameters of SNITCH-T-2007 and the megathrust seismicity parameters of SNITCH-SN is shown in Fig. 3. $N_{t}$ correlates well with the number of earthquakes $N_{e q}(\rho=0.57)$, the seismicity rate $\tau(\rho=0.63)$, and the various measures of the maximum earthquake magnitude $(0.34<\rho<0.46)$. 


\section{tsunamigenic earthquake parameters}
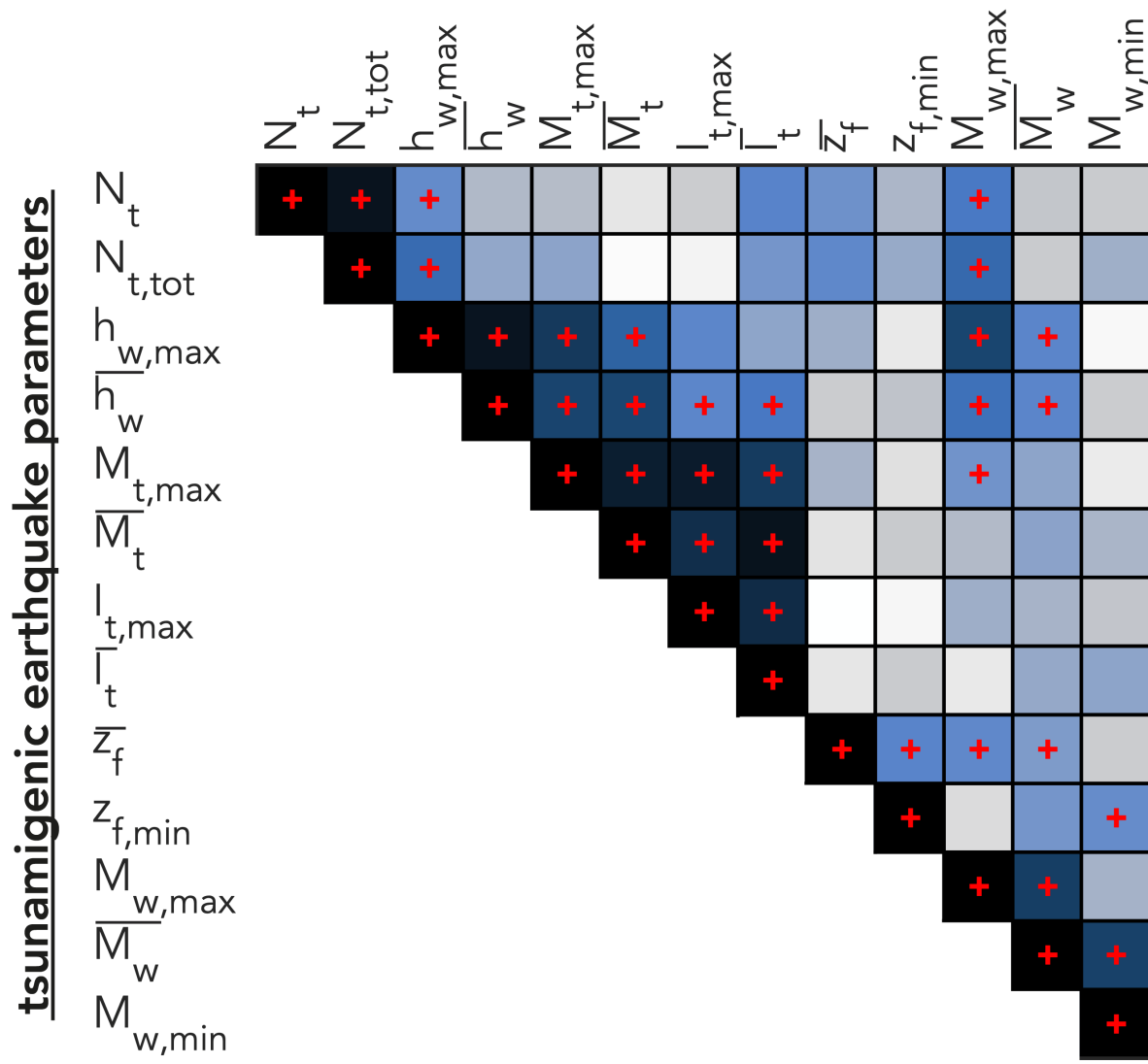

0

0.2

0.4

0.6

0.8

Spearman's rank correlation coefficient $|\rho|$

Figure 2: Spearman's rank correlation coefficients for SNITCH-T-2018: tsunami and tsunamigenic earthquake characteristics correlated with itself. Significant positive and negative correlations worthy of further investigation as defined in Sec. 3.1 are indicated by a red plus and minus sign, respectively. Abbreviations for parameters are explained in Table 2 . 
The maximum water height $h_{w, \max }$ correlates with some megathrust seismicity parameters, such as the cumulative seismic moment $\operatorname{CSM}(\rho=0.45)$, and the equivalent representative magnitude $M_{\operatorname{mrr}}(\rho=0.43)$. This indicates that larger wave heights can be associated with larger earthquakes. The maximum and average maximum magnitude of tsunamigenic earthquakes in a subduction zone correlate well with all the megathrust seismicity measures $(0.3<\rho<0.76)$, with the exception of $M_{\max , \mathrm{Cent} \& \mathrm{CMT}}$ for $\overline{M_{w}}$.

\subsubsection{Geometry of the seismogenic zone and slab}

There are few correlations between the geometric parameters describing the seismogenic zone and subducting slab in SNITCH-SN and the tsunamigenic earthquake parameters of SNITCH-T-2007 (Fig. 3). The only significant correlations are found between the dip of the subduction zone $\theta$ and the average earthquake focal depth $\overline{z_{f}}(\rho=0.46)$. This indicates that a larger dip results in a larger focal depth, which is to be expected as a larger dip of a subducting plate (i.e., a steeper slab) is often associated with a deeper seismogenic zone limit. The negative relationship between $\overline{z_{f}}$ and the radius of curvature $R(\rho=-0.40)$ reflects the same physical explanation. The average and minimum tsunamigenic earthquake magnitude also correlate positively with the dip of the subduction zone.

\subsubsection{Tectonics of the subduction system}

The tectonic parameters describe the large scale structure, geometry, kinematics, and nature of the subduction zone. Since the tectonic parameters are not influenced by a limited observational time span, we correlate them with the SNITCH-T-2018 database (Fig. (4). 
a

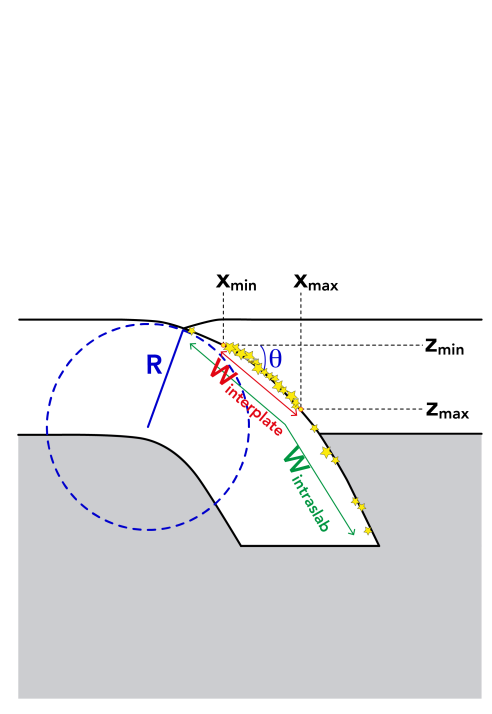

b

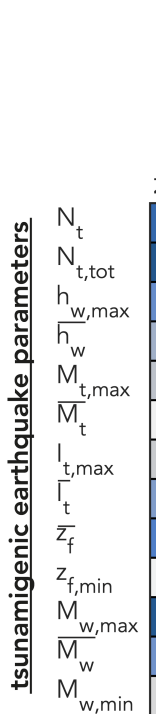

megathrust seismicity parameters

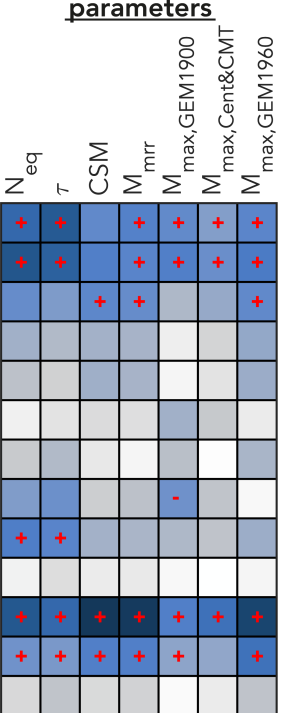

C geometric parameters (based on seismicity)
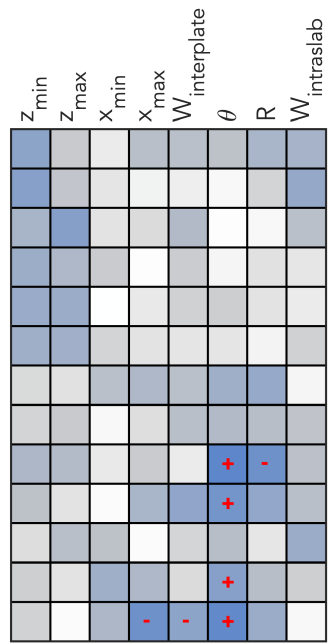

0

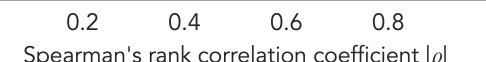

Figure 3: (a) Diagram showing how the geometric parameters in the SNITCH-SN database are estimated based on the extent of megathrust seismicity (yellow stars). (b,c) Spearman's rank correlation coefficients for SNITCH-T-2007 correlated with (b) the megathrust seismicity and (c) the geometric parameters (based on seismicity) of SNITCH-SN. Significant positive and negative correlations worthy of further investigation as defined in Sec. 3.1 are indicated by a red plus and minus sign, respectively. Abbreviations for parameters are explained in Table 2

We find a positive correlation between the type of margin AvsE and $N_{t}$ ( $\rho=0.35)$, which translates to erosional margins being associated more with tsunamigenic earthquakes. This is corroborated by the negative correlation between $N_{t}$ and $T_{\text {sed }}(\rho=-0.40)$.

$N_{t}$ correlates positively with the trench-normal component of the subduction and convergence velocity $\left(v_{\mathrm{sn}}\right.$ and $v_{\mathrm{cn}} ; \rho=0.66$ and $\rho=0.47$, re- 


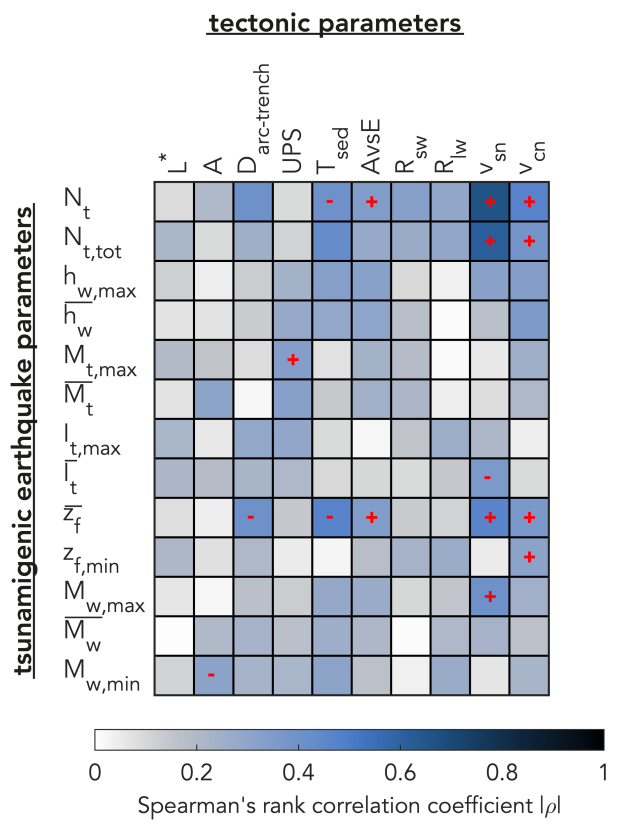

Figure 4: Spearman's rank correlation coefficients for SNITCH-T-2018 correlated with tectonic parameters of SNITCH-SN. Significant positive and negative correlations worthy of further investigation as defined in Sec. 3.1 are indicated by a red plus and minus sign, respectively. Abbreviations for parameters are explained in Table 2 .

spectively), which complies with the assumption that more tsunamigenic earthquakes would be recorded during the same time span in settings where the stress build-up is more rapid. This also holds for non-tsunamigenic earthquakes (McCaffrey, 2008; Corbi et al., 2017b).

The maximum tsunami magnitude correlates positively $(\rho=0.33)$ with the upper plate strain, meaning that compressional upper plates are more often associated with larger tsunami magnitudes. The average focal depth of tsunamigenic earthquakes $\overline{z_{f}}$ shows a negative relationship with $T_{\text {sed }}(\rho=-$ 0.47), and a positive correlation with AvsE $(\rho=0.35)$, indicating erosional 
margins are more associated with a larger average focal depth.

The average focal depth also correlates with both velocity measures. In line with $N_{t}$, the maximum tsunamigenic earthquake magnitude $M_{t \text {,max }}$ correlates with the trench-normal component of the subduction velocity $v_{\text {sn }}$ $(\rho=0.40)$.

Fig. 5 shows scatter plots of $N_{t}$ versus the tectonic parameters (Table 2). There are trends visible between AvsE, $v_{\mathrm{sn}}$, and $v_{\mathrm{cn}}$ versus $N_{t}$ as expected from the high correlations found by the Spearman and Pearson methods. Large $N_{t}$ only occurs for low sediment thickness $T_{\text {sed }}$. There also seems to be a trend for both seafloor roughness parameters, indicating that a rougher seafloor is associated with more tsunamis. This is confirmed by the significant $(p<0.05)$, relatively high $\left(\rho=0.32\right.$ for $R_{\mathrm{sw}}$ and $\rho=0.30$ for $\left.R_{\mathrm{lw}}\right)$ Spearman rank correlations for both $R_{\mathrm{sw}}$ and $R_{\mathrm{lw}}$, although no significant, high correlations are found for the Pearson's coefficient. The two subduction zone segments with the highest normalised number of tsunamis $N_{t}$ are Japan and South-Kuril. Because of their high $N_{t}$, they are often outliers.

\section{Multivariate statistical analysis}

\subsection{Methods}

Following Sandri et al. (2004); Brizzi et al. (2018), we use the Fisher discriminant method (e.g., Duda et al., 1973) to perform a pattern recognition analysis focused at discovering combinations of parameters that could promote the occurrence of tsunamigenic earthquakes. We only consider the tectonic parameters of the SNITCH-SN database to take advantage of the larger amount of data in the corresponding SNITCH-T-2018 database. We exclude 

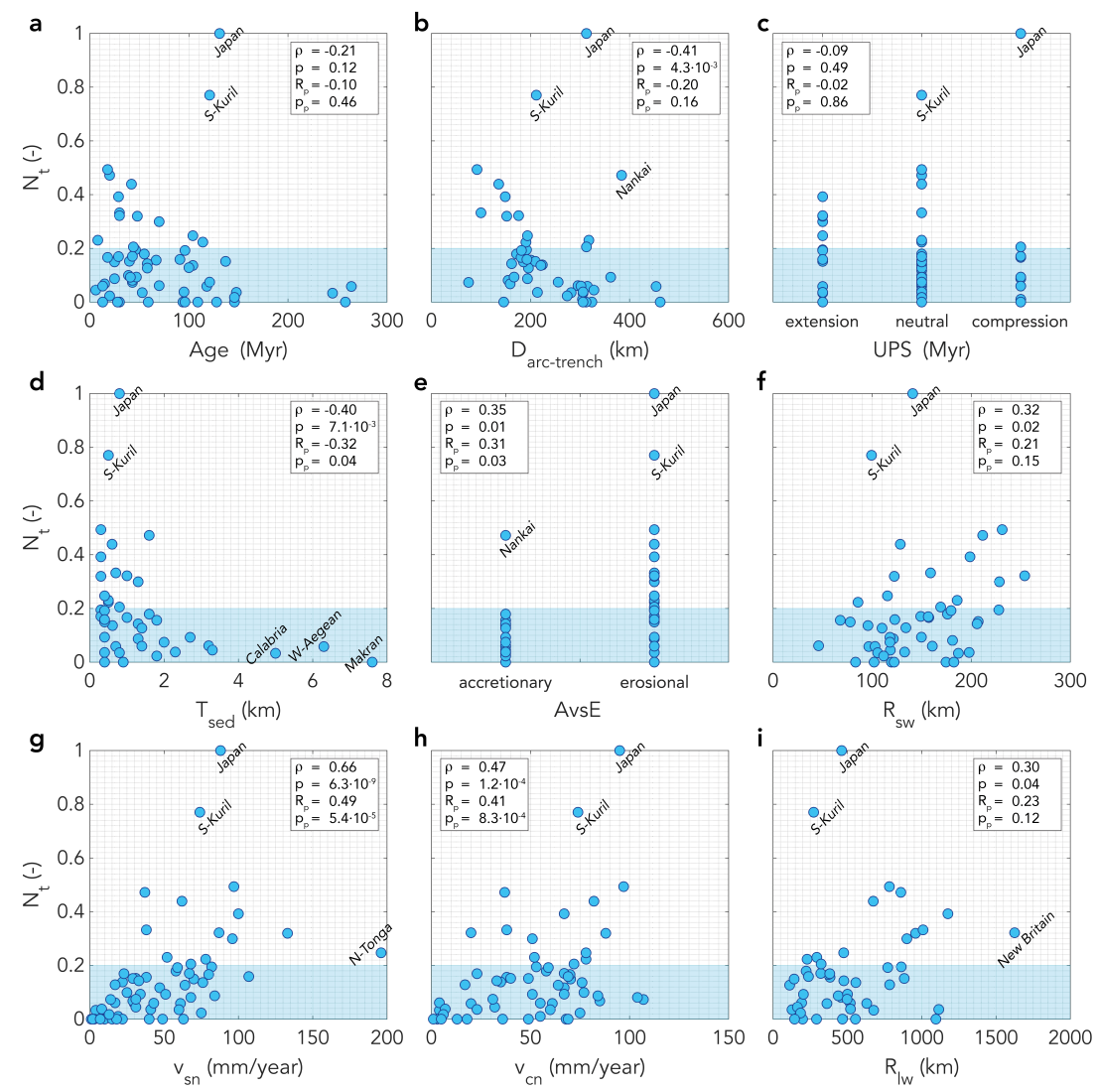

Figure 5: Scatter plots showing the relation between the normalised number of tsunamigenic earthquakes per km trench $N_{t}$ and (a) the age of the subducting plate $A$; (b) the distance between the volcanic arc and the trench $D_{\text {arc-trench }}$ (c) the upper plate strain $U P S$; (d) the sediment thickness at the trench $T_{\text {sed }}$; (e) the type of margin AvsE; (f) the short wavelength (i.e., $12-20 \mathrm{~km}$ ) roughness $R_{\mathrm{sw}}$; (g) the trench-normal component of the subduction velocity $v_{\mathrm{sn}} ;(\mathrm{h})$ the trench-normal component of the convergence velocity $v_{\mathrm{cn}}$; and (i) the long wavelength (i.e., $80-100 \mathrm{~km}$ ) roughness $R_{\mathrm{lw}}$. Each dot represents one of the 62 subduction zone segment. Correlation coefficients and $p$-values are indicated for both the Spearman and Pearson methods. The names of the subduction zone segments are indicated for isolated points in the scatter plots. The threshold of 0.2 for the multivariate analysis is indicated by the blue rectangle. 
$L^{*}$, because this parameter solely depends on the choice of the subduction zone segments and does not represent a physical feature of the subduction system.

We first identify linear combinations that can divide the subduction zone segments in two classes based on $N_{t}$, with class 1 containing subduction zone segments with few tsunamigenic earthquakes (i.e., $N_{t}<0.2$ ), and class 2 containing subduction zone segments with a large number of tsunamigenic earthquakes (i.e., $N_{t} \geq 0.2$ ). The threshold of 0.2 is chosen because it seems to naturally divide the data in the case of the bivariate analysis, as shown in the scatter plots of the age, sediment thickness, and type of margin in Fig. 5 .

The Fisher discriminant analysis typically consists of a learning phase, a voting phase, and control experiments (e.g., Sandri et al., 2004, and references therein). However, following Brizzi et al. (2018), we confine our analysis to the learning phase due to the limited amount of data. During the learning phase, an input set of $n$ parameters is used to identify all the possible linear combinations consisting of $k=1, \ldots, n$ parameters. To distinguish the effect of multiple parameters that could be interdependent, we run 36 Fisher analyses to systematically test the effect of the parameters. The parameters $A$,

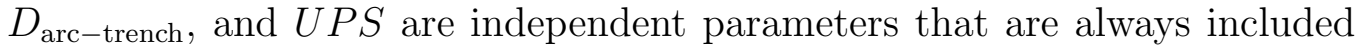
in the analysis. $T_{\text {sed }}$ and AvsE (i.e., the type of margin: accretionary or erosional) are dependent on each other as larger sediment thickness is usually associated with accretionary margins, whereas small sediment thickness is typically associated with erosional margins. Hence, 3 different test cases need to be run: one in which both parameters are included and two where each parameter is included separately. The same reasoning holds for the two 
measures of incoming plate roughness $R_{s w}$ and $R_{l w}$. We adopt a simular reasoning for the velocities $v_{s n}, v_{c n}$, but we also include the option to exclude both velocities from the linear combination, because they could potentially relate to the limited time span of observations in addition to a physical mechanism. This then results in a total of $3 \cdot 3 \cdot 4=36$ different sets of input parameters for the Fisher analysis. For a given set of input parameters, there is one linear combination with a minimum number of parameters $k_{m}$ that minimises the error: the optimal linear combination (Fig. 6). For each analysis, we automatically detect this optimal linear combination when the error reduction by including more parameters into the analysis becomes less than $5 \%$ with respect to the initial error in the case of including only one parameter. Hence, we end up with an optimal linear combination for each of the 36 Fisher analyses. The coefficients in the linear combinations indicate the importance of a parameter in the combination.

To systematically determine which parameters are the most important for generating tsunamigenic earthquakes, we look at three measures: $(i)$ the fraction that a parameter is picked in the best linear combination for a Fisher analysis when it is part of the input; (ii) the normalised average coefficient of a parameter based on all Fisher analyses for which it is included in best linear combination; (iii) the maximum fraction of a consistent sign (i.e., positive or negative) of the coefficient of a parameter to account for the robustness of the effect of the parameter in the linear combination. We define the measure of relative importance $R I$ of a parameter as the multiplication of these three measures. 


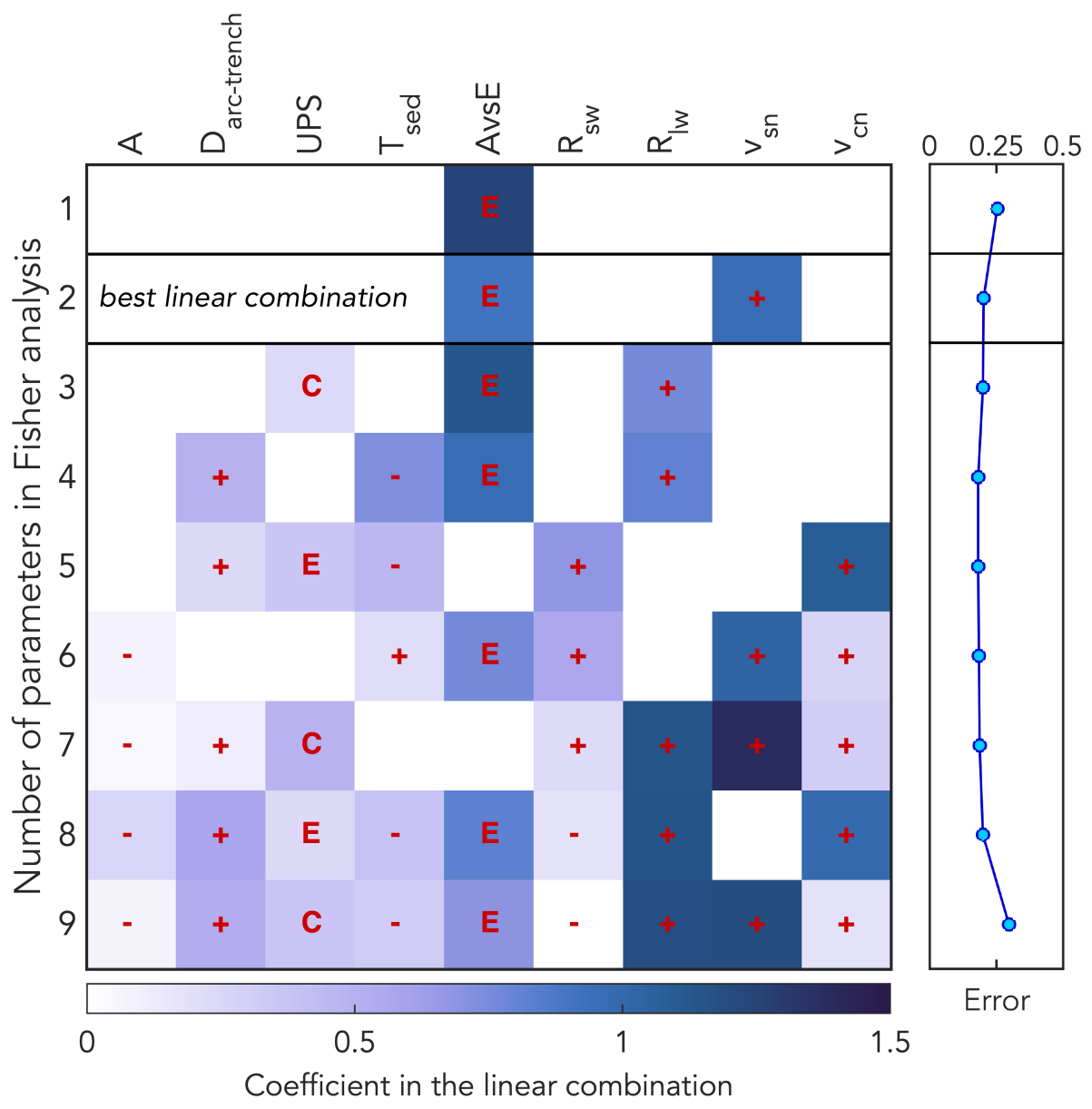

Figure 6: Representative Fisher analysis for one set of input parameters (listed at the top). When a parameter is included in the linear combination, a red symbol indicates how it promotes class $2\left(N_{t} \geq 0.2\right)$. Hence, a plus indicates that larger values of a parameter are associated with class 2 . For discrete parameters, letters indicate the most favourable setting for class 2 (Table 1). The right panel shows the error reduction when more parameters are included in the linear combination. The optimal linear combination for which the error is maximally reduced for the least amount of features included in the linear combination is indicated by black lines. 


\subsection{Results}

Fig. 6 shows the results for one representative Fisher analysis. The input parameters used in the test are indicated at the top, and the resulting coefficients of the linear combinations for different numbers of parameters allowed in the linear combination (on the $y$-axis) is indicated by the colours in each row. Parameters are part of the linear combination when a red symbol is present in the relevant square.

If only one parameter is used to distinguish the two classes of few (class $1 ; N_{t}<0.2$ ) and many (class $2 ; N_{t} \geq 0.2$ ) tsunamigenic earthquakes, the type of margin AvsE is the deciding factor. In this case, an erosional margin is more favourable to produce many tsunamis. When a second parameter is allowed to enter the linear combination that divides the two classes, the trench-normal component of the subduction velocity is picked by the Fisher algorithm. The positive coefficient indicates that a large subduction velocity correlates to class 2 , i.e., many tsunamigenic earthquakes. These two parameters, AvsE and $v_{\mathrm{sn}}$, also exhibited high correlations in the bivariate analysis (Sec. 3.2.4). The combination of these two parameters is also the optimal linear combination as defined in Sec. 4.1. The error is namely reduced the most with respect to the least amount of features required to divide the two classes. When a third parameter enters the linear combination, the upper plate strain $U P S$ is picked by the Fisher analysis. An overriding plate that experienced compression is associated with many tsunamis. Simultaneously, the long wavelength roughness $R_{\mathrm{lw}}$ is picked instead of the subduction velocity, indicating that a rougher incoming plate is associated with the class of many tsunamis. With four parameters, the upper plate strain is removed 
from the linear combination, and instead the sediment thickness $T_{\text {sed }}$ and the distance between the volcanic arc and the trench $D_{\text {arc-trench }}$ are picked. As $D_{\text {arc-trench }}$ can be related to the dip of a slab, with large $D_{\text {arc-trench }}$ being associated with a more shallowly dipping slab, a positive coefficient in the linear combination could hint at a relationship between shallowly dipping slabs and tsunamigenic earthquakes. The negative coefficient of the sediment thickness $T_{\text {sed }}$ associated here with many tsunamis is in line with the erosional margin that is consistently present in almost all linear combinations. When all 9 parameters are included in the linear combination, which is theoretically possible, the error is higher compared to the best linear combination. This indicates that including more parameters into the linear combination does not necessarily improve it. Also note that the parameters chosen for the linear combinations can differ completely when a different number of parameters is allowed for the linear combination. The sign of the parameter can also change for different numbers of parameters. When the sign consistently remains the same over all linear combinations and Fisher analyses, we deem the effect of the parameter on dividing the two classes to be robust. In summary, for the example Fisher analysis of Fig. 6, the linear combination that best describes the difference between the two classes with these parameters as input consists of the type of margin and the subduction velocity.

When we consider all 36 Fisher analyses, the amount of parameters included in the best linear combination is on average 2.9. The maximum amount of parameters included in the optimal linear combination is 6 . The error associated with the best linear combination is on average 0.22 . This corresponds to an average of 10.5 segments (25.6\%) that are classified in the 
wrong class according to the optimal linear combination. The best linear combinations for each of the 36 Fisher analyses that were run for different combinations of input parameters are shown in Fig. 7. Several variables appear to stand out, such as the type of margin (consistently erosional) and the subduction velocity (consistently positive). We summarise the main findings of these 36 analyses in Fig. 8, by calculating the relative importance of each parameter as described in Sec. 4.1.

The most important parameter, with a relative importance of 0.86 , is the type of margin, i.e., accretionary or erosional. When it is included in the input parameters of the Fisher analysis, it is picked $95.8 \%$ of the time in the best linear combination. After that, the second most important parameter is the trench-normal component of the subduction velocity with relative importance 0.66 , which is picked $66.7 \%$ of the time. The third most important parameter is the sediment thickness with $R I=0.46$, which is picked $50 \%$ of the time. The long wavelength roughness has a relative importance of 0.32 and the trench-normal component of the convergence velocity has $R I=0.28$. The other parameters show low measures of relative importance with $R I<0.1$. Hence, based on these results, subduction zones are more prone to host tsunamigenic earthquakes at an erosional margin with few sediments and a rough incoming seafloor in a rapidly converging system.

\section{Discussion}

We compiled the SNITCH database consisting of tsunami characteristics, tsunamigenic earthquake parameters, megathrust seismicity, seismogenic zone geometry, and tectonic parameters of subduction zones across 


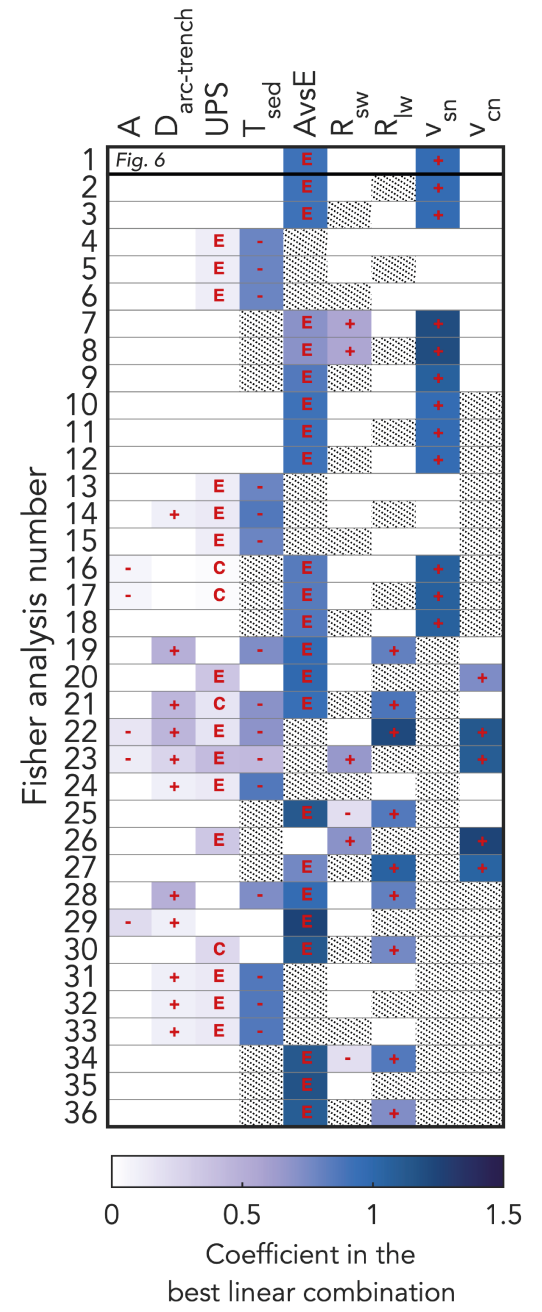

Figure 7: The best linear combination for each Fisher analysis. When a parameter is included in the linear combination, a red symbol indicates how it promotes class $2\left(N_{t} \geq\right.$ 0.2 ). Hence, a plus indicates that larger values of a parameter are associated with class 2 . For discrete parameters, letters indicate the most favourable setting for class 2 (Table 1). If parameters are not included in the input for a test, the area is dotted. Note that the best linear combination of Fig. 6 is included here as well and highlighted by horizontal black lines. 


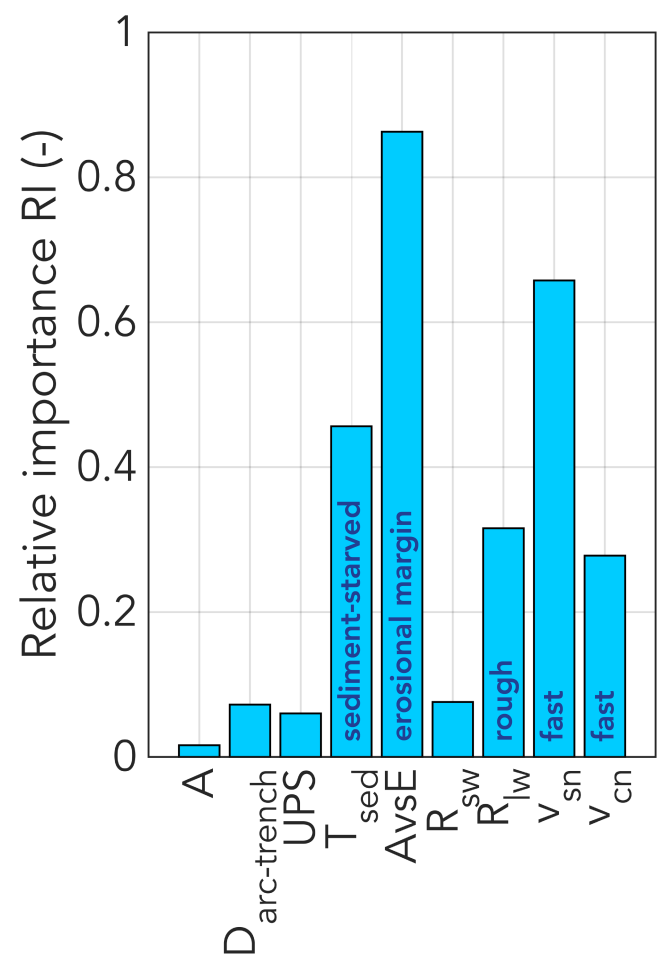

Figure 8: The relative importance of parameters (Sec. 4.1) as calculated from the Fisher analyses presented in Fig. 7. For parameters with a relative importance $R I>0.2$, text in the bars indicates how the parameter promotes many tsunamigenic earthquakes (class 2).

the world. The bivariate analysis (Sec. 3) shows that the normalised number of tsunamis per $\mathrm{km}$ trench $N_{t}$ correlates with some of the interplate seismicity and tectonic parameters in SNITCH-SN. However, $N_{t}$ shows no correlation with the geometric parameters describing the seismogenic zone. Specifically, meaningful correlations are found with the type of margin (i.e., accretionary or erosional), the trench-normal components of the subduction and convergence velocity of the subduction zone, the sediment thickness, seismicity rate, and measures of maximum earthquake magnitude in a subduction zone 
segment.

The multivariate analysis of the tectonic parameters points towards the same parameters identified in the bivariate analysis and to the incoming plate roughness, to distinguish subduction zones with a lower $\left(N_{t}<0.2\right)$ and higher number of tsunamigenic earthquakes $\left(N_{t} \geq 0.2\right)$. Specifically, we find that rough incoming plates at erosional margins, in rapidly converging systems have produced more tsunamigenic earthquakes during the analysed time span.

In the following, we discuss which - if any - tectonic setting is more favourable for tsunamigenic earthquakes and how this could affect tsunamigenesis. We also speculate which kind of fault is likely to be the most important in producing tsunamigenic earthquakes, because we did not find a correlation with the seismogenic zone geometry parameters.

\subsection{Are there specific tectonic settings where more tsunamigenic earthquakes} have been observed?

We find multiple significant correlations and patterns in both the bivariate and multivariate analyses, indicating that certain parameters are indeed correlated with an increased amount of observed tsunamis. So, we show that there are indeed specific tectonic settings where more tsunamigenic earthquakes have been observed. Therefore, we speculate that there are specific tectonic settings that could be more prone to host tsunamigenic earthquakes (Sec. 5.2). However, most scatter plots still contain outliers (Fig. 5) and there are always at least 8 segments incorrectly classified in the multivariate analysis (Sec. 4.2). Besides that, for some parameters no clear correlation can be discerned at all. This is partly due to the limited amount of data for the 62 


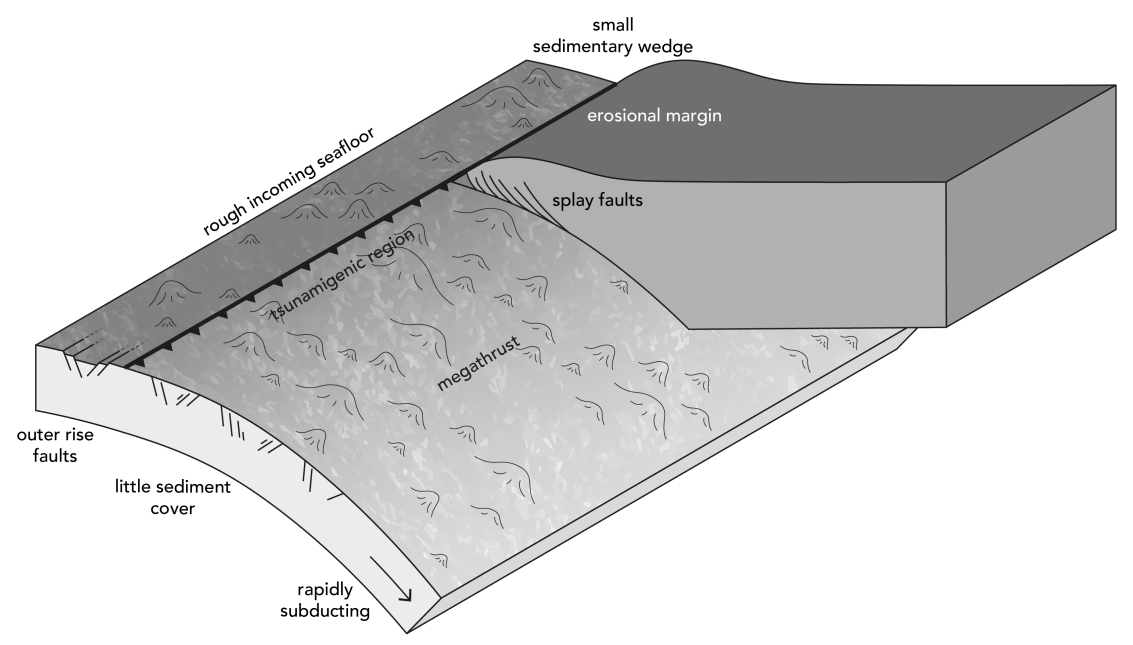

Figure 9: Cartoon of a tectonic setting more prone to host tsunamigenic earthquakes. A subducting slab with little sediments and a rough incoming seafloor subducts relatively rapidly beneath a continental plate at an erosional margin.

subduction zone segments. Most parameters in the SNITCH database do not have values for each subduction zone segment due to a lack of observations.

In addition, we only consider a limited observational time span for the data in this study, with the earthquake data limited to 1900-2007 and the tsunami data limited to 1962-2018 (or, for comparison to the earthquake parameters, 2007). This time span is constrained due to the availability of global observations and could incur a bias in our results.

Interestingly, the seismogenic zone geometry parameters (Sec. 3.2.3) do not correlate with $N_{t}$, which can have different explanations. First, it might be that the amount of data present in our tsunami databases is too scarce to result in any significant correlation (Fig. 3). However, other parameters do show significant correlations, so this option is not necessarily true. An alter- 
native explanation might be that the megathrust is not the most important fault in tsunamigenesis. Because of that, the seismogenic zone parameters that define the potential slip area on the megathrust do not correlate with $N_{t}$. We explore this option in more detail in Sec. 5.3 .

\subsection{Which tectonic setting is more prone to host tsunamigenic earthquakes?}

Our analysis shows that subduction zones where the incoming plate subducts rapidly at an erosional margin are more prone to generate tsunamis through earthquakes (Fig, 9p. Our analysis also highlights the importance of having a thin sediment layer in the subduction segment in order to be associated with more tsunamigenic earthquakes. The effect of a thin sediment layer on tsunamigenic earthquake occurrence in subduction zones fits well with the importance of erosional margins, because sediment-starved trenches are often associated with erosional margins. However, this does not mean that erosional margins are completely devoid of sediment cover (Clift and Vannucchi, 2004). It has been suggested that the presence of sediments could enhance tsunamigenesis, by promoting larger uplift (Ma and Nie, 2019). This could explain the large range of $N_{t}$ for subduction zone segments with moderate sediment cover (i.e., $T_{\text {sed }} \leq 2 \mathrm{~km}$; Fig. 5d). Therefore, erosional margins with a small sedimentary wedge may be more prone to host tsunamigenic earthquakes. The negative correlation between sediment thickness and the amount of normalised tsunamis in a subduction zone segment could also be related to the effect of sediment thickness on the recurrence time of earthquakes (Brizzi et al., 2017). Their numerical models show that less sediment cover results in a smaller seismogenic zone with a shorter recurrence interval. Here, we find that subduction zone segments with a thick sedimentary 
layer — and, presumably, a larger recurrence interval — have produced less tsunamis, which could be a result of the limited observational time span of the SNITCH database (Sec. 5.1). One outlier that is apparent in Fig. 5e is the Nankai subduction segment, which has produced relatively many tsunamis even though it is an accretionary margin rather than erosional. However, the Nankai segment has experienced periods of erosion (Clift and Vannucchi, 2004), which might explain why it has experienced more tsunamis than the other accretionary margins. The Nankai subduction segment is also characterised by a rough subducting plate with many topographical features such as seamounts (Yokota et al., 2016). Since we find that rough subducting plates are associated with more tsunamigenic earthquakes, this could also contribute towards the reason as to why Nankai is an outlier.

The importance of the trench-normal components of the subduction and convergence velocity can be explained through the general relationship between earthquakes and tsunamis also found in the bivariate analysis (Sec. 3.2 , Fig. 3). In a subduction zone with a high subduction or convergence velocity, the stresses are built up faster and hence released more often in earthquakes, resulting in a shorter recurrence interval. More earthquakes generally means a larger likelihood of those earthquakes producing tsunamis. Since our study is restricted to a specific time interval for tsunamigenic earthquake observations, it is indeed likely that the subduction zones with a higher convergence velocity have produced more tsunamigenic earthquakes in this time period (McCaffrey, 2008; Corbi et al., 2017a). An alternative explanation for the importance of the velocities could be that large convergence velocities are typically associated with erosional margins (Clift and Vannucchi, 2004). Since 
we find that erosional margins are the most important factor for increased tsunamigenesis, it follows that the two aspects associated most with erosional margins, i.e., fast convergence and a thin sediment cover, are also highlighted in our analysis as important factors for tsunamigenesis.

Other studies have already linked sediment thickness at the trench and seafloor roughness to tsunami earthquakes (Tanioka et al., 1997; Polet and Kanamori, 2000). The combination of a thin sediment layer at the trench and a rough seafloor in particular has already been pointed out for 13 tsunami earthquake regions at 7 different subduction zones (i.e., Sumatra, Java, Hokkaido and the Kurils, Aleutians, Nicaragua, Peru, and New Zealand) by Geersen (2019). They looked at structural similarities between marine acoustic data. Our study strengthens this view by providing the first global, statistical analysis of the effect of these parameters on tsunamigenic earthquakes, which include both tsunami earthquakes and large megathrust earthquakes that caused tsunamis. The amount of trench sediments and the roughness of the seafloor are often considered as related, because thick piles of sediment entering the trench could potentially smooth out the topography on the incoming plate (Ruff, 1989). It is generally thought that a rough incoming seafloor and lack of sediments leads to a complex, heavily fractured shallow subduction interface (Dominguez et al., 1998; Wang and Bilek, 2011, 2014; Ruh et al. 2016). Such a heavily fractured environment could promote tsunamigenic earthquakes, because of the increased presence of splay faults that can accommodate large vertical displacement. 


\subsection{Which type of fault produces tsunamigenic earthquakes?}

Large tsunamis have been caused by large earthquakes that ruptured the megathrust, such as the $2004 M_{w}$ 9.1-9.3 Sumatra-Andaman (e.g., Lay et al., 2005, Titov et al., 2005), $2010 M_{w} 8.8$ Maule (e.g., Delouis et al., 2010), and $2011 M_{w} 9.0$ Tōhoku-Oki earthquake (e.g., Fujii et al., 2011; Ozawa et al., 2011). They have also been caused by smaller earthquakes that potentially ruptured outer rise or splay faults, such as the $1933 M_{\mathrm{w}} 8.4$ Sanriku (Kanamori, 1971), 1946 Unimak Alaska (von Huene et al., 2016), and 2006 Java (Fan et al., 2017) tsunami earthquakes. Simultaneously, splay faults could also play a role during large megathrust earthquakes, as suggested for the $2004 M_{w}$ 9.1-9.3 Sumatra-Andaman (DeDontney and Rice, 2012; Waldhauser et al., 2012) and the $2010 M_{w} 8.8$ Maule (Melnick et al., 2012) earthquakes.

Our study shows a lack of correlations between $N_{t}$ and the seismogenic zone geometry parameters, as discussed in Sec. 5.1. This could result from the fact that the megathrust is not the most important fault to produce tsunamigenic earthquakes. Indeed, many studies have proposed that outer rise or splay faults play an important role for tsunamigenesis (e.g., Fukao, 1979; Wendt et al. 2009; Sladen and Trevisan, 2018). Slip on these types of faults, which are typically steeper than the megathrust, could result in larger vertical displacement compared to megathrust events. This could explain the discrepancy between earthquake moment magnitude and tsunami magnitude observed during tsunami earthquakes (Kanamori, 1972). It could also explain why we find that erosional margins have produced more tsunamigenic earthquakes, since they are typically associated with a heavily fractured environ- 
ment including splay faults. Hence, we speculate that faults other than the megathrust might play an equally, or more, important role in tsunamigenesis.

\section{Conclusions}

We compiled the SNITCH database, which contains global data on earthquake and tectonic subduction zone features, tsunamis, and tsunamigenic earthquakes for 62 subduction segments. In the performed bivariate analysis, we find correlations between the normalised number of tsunamigenic earthquakes per $\mathrm{km}$ trench $N_{t}$ of the SNITCH-T database and some of the tectonic parameters of the SNITCH-SN database (i.e., the type of margin: accretionary or erosional, the trench-normal components of the subduction and convergence velocity, and the sediment thickness at the trench).

The multivariate analysis explores the relationships between the tectonic parameters and the tsunamigenic potential of a subduction zone further. The type of margin (i.e., erosional or accretionary) and the subduction and convergence velocity normal to the trench are the most crucial parameters to sort the subduction zones between a class with few tsunamigenic earthquakes $\left(N_{t}<0.2\right)$ and a class with many tsunamigenic earthquakes $\left(N_{t} \geq 0.2\right)$. Other parameters of secondary importance for this division are the long wavelength roughness and the sediment thickness at the trench. Tsunamigenic earthquakes therefore appear to be more common in rapidly converging, erosional subduction settings, with a rough incoming plate and low amounts of sediments at the trench. These settings are characterised by heavily fractured and complex, heterogeneous shallow subduction interfaces arising from the rough seafloor and the lack of sediments smoothing the interface. Tsunami- 
genic earthquakes may be more common in such settings, because of the presence of more splay faults, which could accommodate larger vertical displacements.

\section{Acknowledgements}

We would like to thank Andreas Fichtner for fruitful discussions and support that greatly improved this work. We are also grateful to Arnauld Heuret, Claudia Piromallo, and Serge Lallemand, for providing and helping with the SNITCH-SN database. We thank Laura Sandri for helping with setting up the Fisher analysis.

This work is part of the ASCETE project funded by the Volkswagen Foundation (Advanced Simulation of Coupled Earthquake-Tsunami Events, grant no 88479). The grant to the Department of Science, Roma Tre University (MIUR-Italy Dipartimenti di Eccellenza, articolo 1, commi 314 - 337, legge 232/2016) is gratefully acknowledged by FF, SB and EvR.

The SNITCH database is included in the Supplementary Material of this article.

\section{References}

Bell, R., Holden, C., Power, W., Wang, X., Downes, G., 2014. Hikurangi margin tsunami earthquake generated by slow seismic rupture over a subducted seamount. Earth and Planetary Science Letters 397, 1 - 9. URL: http://wWw.sciencedirect.com/science/article/ pii/S0012821X14002313, doi:https://doi.org/10.1016/j.epsl.2014. 04.005 . 
Bilek, S.L., 2010. The role of subduction erosion on seismicity. Geology 38, $479-480$.

Bilek, S.L., Lay, T., 1999. Rigidity variations with depth along interplate megathrust faults in subduction zones. Nature 400, 443.

Bilek, S.L., Lay, T., 2002. Tsunami earthquakes possibly widespread manifestations of frictional conditional stability. Geophysical Research Letters $29,18-1$.

Brizzi, S., Sandri, L., Funiciello, F., Corbi, F., Piromallo, C., Heuret, A., 2018. Multivariate statistical analysis to investigate the subduction zone parameters favoring the occurrence of giant megathrust earthquakes. Tectonophysics 728, 92-103.

Brizzi, S., van Zelst, I., van Dinther, Y., Funiciello, F., Corbi, F., 2017. How long-term dynamics of sediment subduction controls short-term dynamics of seismicity, in: AGU Fall Meeting Abstracts.

Clift, P., Vannucchi, P., 2004. Controls on tectonic accretion versus erosion in subduction zones: Implications for the origin and recycling of the continental crust. Reviews of Geophysics 42.

Corbi, F., Funiciello, F., Brizzi, S., Lallemand, S., Rosenau, M., 2017a. Control of asperities size and spacing on seismic behavior of subduction megathrusts. Geophysical Research Letters 44.

Corbi, F., Herrendörfer, R., Funiciello, F., Van Dinther, Y., 2017b. Controls of seismogenic zone width and subduction velocity on interplate seismicity: 
Insights from analog and numerical models. Geophysical Research Letters 44, 6082-6091.

DeDontney, N., Rice, J.R., 2012. Tsunami wave analysis and possibility of splay fault rupture during the 2004 Indian Ocean earthquake. Pure and applied geophysics 169, 1707-1735.

Delouis, B., Nocquet, J.M., Vallée, M., 2010. Slip distribution of the February 27, $2010 \mathrm{Mw}=8.8$ Maule earthquake, central Chile, from static and highrate GPS, InSAR, and broadband teleseismic data. Geophysical Research Letters 37.

DeMets, C., Gordon, R.G., Argus, D., Stein, S., 1990. Current plate motions. Geophysical journal international 101, 425-478.

Dominguez, S., Lallemand, S., Malavieille, J., von Huene, R., 1998. Upper plate deformation associated with seamount subduction. Tectonophysics 293, 207-224.

Duda, R.O., Hart, P.E., Stork, D.G., 1973. Pattern classification and scene analysis. volume 3. Wiley New York.

Fan, W., Bassett, D., Jiang, J., Shearer, P.M., Ji, C., 2017. Rupture evolution of the 2006 Java tsunami earthquake and the possible role of splay faults. Tectonophysics 721, 143-150.

Faulkner, D., Mitchell, T., Behnsen, J., Hirose, T., Shimamoto, T., 2011. Stuck in the mud? Earthquake nucleation and propagation through accretionary forearcs. Geophysical Research Letters 38. 
Fujii, Y., Satake, K., Sakai, S., Shinohara, M., Kanazawa, T., 2011. Tsunami source of the 2011 off the Pacific coast of Tohoku Earthquake. Earth, planets and space 63,55 .

Fukao, Y., 1979. Tsunami earthquakes and subduction processes near deepsea trenches. Journal of Geophysical Research: Solid Earth 84, 2303-2314.

Gahalaut, V., Subrahmanyam, C., Kundu, B., Catherine, J., Ambikapathy, A., 2010. Slow rupture in Andaman during 2004 Sumatra-Andaman earthquake: a probable consequence of subduction of 90E ridge. Geophysical Journal International 180, 1181-1186.

Geersen, J., 2019. Sediment-starved trenches and rough subducting plates are conducive to tsunami earthquakes. Tectonophysics 762, 28-44.

Global Historical Tsunami Database, Retrieved: February 1, 2019. National Geophysical Data Center / World Data Service (NGDC/WDS). Doi:10.7289/V5PN93H7.

Global Tsunami Database, 2100 BC to Present ,2019. Novosibirsk Tsunami Laboratory of the Institute of Computational Mathematics and Mathematical Geophysics of Siberian Division of Russian Academy of Sciences. Http://tsun.sscc.ru/nh/tsunami.php.

Gusiakov, V.K., Dunbar, P.K., Arcos, N., 2019. Twenty-five years (19922016) of global tsunamis: Statistical and analytical overview. Pure and Applied Geophysics , 1-13. 
Heuret, A., Conrad, C., Funiciello, F., Lallemand, S., Sandri, L., 2012. Relation between subduction megathrust earthquakes, trench sediment thickness and upper plate strain. Geophysical Research Letters 39.

Heuret, A., Lallemand, S., Funiciello, F., Piromallo, C., Faccenna, C., 2011. Physical characteristics of subduction interface type seismogenic zones revisited. Geochemistry, Geophysics, Geosystems 12.

von Huene, R., Miller, J.J., Klaeschen, D., Dartnell, P., 2016. A possible source mechanism of the 1946 Unimak Alaska far-field tsunami: uplift of the mid-slope terrace above a splay fault zone, in: Global Tsunami Science: Past and Future, Volume I. Springer, pp. 4189-4201.

Iida, K., Cox, D.C., Pararas-Carayannis, G., 1967. Preliminary catalog of tsunamis occurring in the Pacific Ocean. Technical Report. DTIC Document.

Kanamori, H., 1971. Seismological evidence for a lithospheric normal faulting - The Sanriku earthquake of 1933. Physics of the Earth and Planetary Interiors 4, 289-300.

Kanamori, H., 1972. Mechanism of tsunami earthquakes. Physics of the earth and planetary interiors 6, 346-359.

Lallemand, S., Peyret, M., Van Rijsingen, E., Arcay, D., Heuret, A., 2018. Roughness characteristics of oceanic seafloor prior to subduction in relation to the seismogenic potential of subduction zones. Geochemistry, Geophysics, Geosystems 19, 2121-2146. 
Lay, T., Kanamori, H., Ammon, C.J., Koper, K.D., Hutko, A.R., Ye, L., Yue, H., Rushing, T.M., 2012. Depth-varying rupture properties of subduction zone megathrust faults. Journal of Geophysical Research: Solid Earth 117.

Lay, T., Kanamori, H., Ammon, C.J., Nettles, M., Ward, S.N., Aster, R.C., Beck, S.L., Bilek, S.L., Brudzinski, M.R., Butler, R., et al., 2005. The great Sumatra-Andaman earthquake of 26 December 2004. Science 308, $1127-1133$.

Ma, S., Nie, S., 2019. Dynamic Wedge Failure and Along-Arc Variations of Tsunamigenesis in the Japan Trench Margin. Geophysical Research Letters .

McCaffrey, R., 2008. Global frequency of magnitude 9 earthquakes. Geology $36,263-266$.

Melnick, D., Moreno, M., Motagh, M., Cisternas, M., Wesson, R.L., 2012. Splay fault slip during the Mw 8.82010 Maule Chile earthquake. Geology 40, 251-254.

Ozawa, S., Nishimura, T., Suito, H., Kobayashi, T., Tobita, M., Imakiire, T., 2011. Coseismic and postseismic slip of the 2011 magnitude-9 Tohoku-Oki earthquake. Nature 475, 373.

Polet, J., Kanamori, H., 2000. Shallow subduction zone earthquakes and their tsunamigenic potential. Geophysical Journal International 142, 684-702.

Robinson, D., Das, S., Watts, A., 2006. Earthquake rupture stalled by a subducting fracture zone. Science 312, 1203-1205. 
Ruff, L., Kanamori, H., 1980. Seismicity and the subduction process. Physics of the Earth and Planetary Interiors 23, 240-252.

Ruff, L.J., 1989. Do trench sediments affect great earthquake occurrence in subduction zones?, in: Subduction Zones Part II. Springer, pp. 263-282.

Ruh, J.B., Sallarès, V., Ranero, C.R., Gerya, T., 2016. Crustal deformation dynamics and stress evolution during seamount subduction: Highresolution 3-d numerical modeling. Journal of Geophysical Research: Solid Earth 121, 6880-6902.

Sahakian, V., Melgar, D., Muzli, M., 2019. Weak near-field behavior of a tsunami earthquake: Towards real-time identification for local warning. Geophysical Research Letters .

Sandri, L., Marzocchi, W., Zaccarelli, L., 2004. A new perspective in identifying the precursory patterns of eruptions. Bulletin of volcanology 66, $263-275$.

Satake, K., 2015. 4.19 - tsunamis, in: Schubert, G. (Ed.), Treatise on Geophysics (Second Edition). second edition ed.. Elsevier, Oxford, pp. 477 - 504. URL: http://wWW.sciencedirect.com/science/ article/pii/B9780444538024000865, doi:https://doi.org/10.1016/ B978-0-444-53802-4.00086-5.

Satake, K., Tanioka, Y., 1999. Sources of tsunami and tsunamigenic earthquakes in subduction zones. Pure and Applied Geophysics 154, 467-483.

Scholl, D.W., Kirby, S.H., von Huene, R., Ryan, H., Wells, R.E., Geist, E.L., 2015. Great $(>=$ Mw8.0) megathrust earthquakes and the subduction 
of excess sediment and bathymetrically smooth seafloor. Geosphere 11, $236-265$.

Seno, T., 2002. Tsunami earthquakes as transient phenomena. Geophysical research letters 29.

Sibuet, J.C., Rangin, C., Le Pichon, X., Singh, S., Cattaneo, A., Graindorge, D., Klingelhoefer, F., Lin, J.Y., Malod, J., Maury, T., et al., 2007. 26th December 2004 great Sumatra-Andaman earthquake: Co-seismic and post-seismic motions in northern Sumatra. Earth and Planetary Science Letters 263, 88-103.

Sladen, A., Trevisan, J., 2018. Shallow megathrust earthquake ruptures betrayed by their outer-trench aftershocks signature. Earth and Planetary Science Letters 483, 105-113.

Soloviev, S., Go, C.N., 1974. Catalog of tsunamis in western coast of the Pacific Ocean. Academy of Sciences, USSR, Izdat. Nauka , 1-130.

Storchak, D.A., Di Giacomo, D., Bondár, I., Engdahl, E.R., Harris, J., Lee, W.H., Villaseñor, A., Bormann, P., 2013. Public release of the ISC-GEM global instrumental earthquake catalogue (1900-2009). Seismological Research Letters 84, 810-815.

Tanioka, Y., Ruff, L., Satake, K., 1997. What controls the lateral variation of large earthquake occurrence along the Japan Trench? Island Arc 6, $261-266$.

Tanioka, Y., Seno, T., 2001. Sediment effect on tsunami generation of the 
1896 Sanriku tsunami earthquake. Geophysical Research Letters 28, 33893392.

Titov, V., Rabinovich, A.B., Mofjeld, H.O., Thomson, R.E., González, F.I., 2005. The global reach of the 26 December 2004 Sumatra tsunami. Science 309, 2045-2048.

Van Rijsingen, E., Lallemand, S., Peyret, M., Arcay, D., Heuret, A., Funiciello, F., Corbi, F., 2018. How subduction interface roughness influences the occurrence of large interplate earthquakes. Geochemistry, Geophysics, Geosystems 19, 2342-2370.

Waldhauser, F., Schaff, D.P., Diehl, T., Engdahl, E.R., 2012. Splay faults imaged by fluid-driven aftershocks of the $2004 \mathrm{Mw} 9.2$ Sumatra-Andaman earthquake. Geology 40, 243-246.

Wang, K., Bilek, S.L., 2011. Do subducting seamounts generate or stop large earthquakes? Geology 39, 819-822.

Wang, K., Bilek, S.L., 2014. Invited review paper: Fault creep caused by subduction of rough seafloor relief. Tectonophysics 610, 1-24.

Wendt, J., Oglesby, D.D., Geist, E.L., 2009. Tsunamis and splay fault dynamics. Geophysical Research Letters 36.

Yokota, Y., Ishikawa, T., Watanabe, S.i., Tashiro, T., Asada, A., 2016. Seafloor geodetic constraints on interplate coupling of the Nankai Trough megathrust zone. Nature 534, 374 . 